Jurnal Pengabdian Masyarakat Sains Indonesia

\title{
Sosialisasi Berbagai Jenis Kupu-Kupu Indah Sebagai Materi Pengayaan Keanekaragaman Hayati di SMPN Sekitar Kawasan Taman Wisata Alam Suranadi
}

\author{
Mohammad Liwa Ilhamdi ${ }^{1 *}$, Agil Al Idrus ${ }^{1}$, Didik Santoso ${ }^{1}$, Lalu Zulkifli ${ }^{1}$, I Wayan Mertha ${ }^{1}$ \\ ${ }^{\text {I}}$ Program Studi Pendidikan Bilogi, FKIP Universitas Mataram, Mataram, Indonesia
}

DOI: https://doi.org/10.29303/jpmsi.v2i2.79

Citation: Ilhamdi, M., L., Idrus, A., A., Santoso, S., Zulkifli, L., Mertha, I., W. 2020. Sosialisasi Berbagai Jenis KupuKupu Indah Sebagai Materi Pengayaan Keanekaragaman Hayati di SMPN Sekitar Kawasan Taman Wisata Alam Suranadi. Jurnal Pengabdian Masyarakat Sains Indonesia (JPMSI). 2(2):137-142.

\section{Article history}

Received: November $01^{\text {th }} 2020$

Revised: November $10^{\text {th }} 2020$

Accepted: November $23^{\text {th }} 2020$

*Corresponding Author:

Mohammad Liwa Ilhamdi, FKIP Universitas Mataram, Mataram, Indonesia;

Email:

liwa_ilhamdi@unram.ac.id
Abstrak: Pembelajaran materi keanekaragaman hayati yang kontekstual di sekolah sekitar Taman Wisata Alam Suranadi belum dilakukan karena tidak ada buku dan media VCD pembelajaran kontekstual yang menyajikan keanekaragaman hayati di sekitar sekolah. Faktor ini yang menjadi permasalahan utama mitra dan tawaran penyelesaiannya adalah dengan mensosialisasikan keanekaragaman hayati khususnya kupu-kupu yang ada di sekitar sekolah. Pembelajaran yang menyenangkan berbasis lingkungan sekitar atau CTL (Contextual Teaching and Learning) karena siswa dapat melihat secara nyata, mengalami sendiri materi pelajaran yang ada di sekitar lingkungannya. selanjutnya dengan CTL dapat meningkatkan hasil belajar Siswa dibelajarkan dengan buku dan VCD yang berisi materi pelajaran yang ada di sekitar siswa. Hasil belajar siswa di SMPN sekitar taman wisata Suranadi masih di bawah standar KKM 75. Metode kegiatan ini adalah sosialisasi dengan penjelasan, penyajian isi buku dan penayangan VCD Pembelajaran, tanya jawab dan diskusi. Tujuan dari kegiatan ini untuk mensosialisasikan berbagai jenis kupu-kupu indah sebagai materi pengayaan keanekaragaman hayati di SMPN sekitar kawasan Taman Wisata Alam Suranadi. Setelah selesainya pelaksanaan kegiatan ini juga akan dilaksanakan pendampingan pembelajaran yang dilakukan guru untuk melaksanakan pembelajaran berbasis lingkungan. Hasil pengabdian sebagai berikut 1) telah dilakukan sosialisasi berbagai jenis kupu-kupu indah sebagai materi pengayaan keanekaragaman hayati di SMPN sekitar kawasan Taman Wisata Alam Suranadi 2) peserta kegiatan pengabdian $100 \%$ mengikuti, menanggapi dan memahami materi sosialisasi. Kesimpulan sosialisasi berbagai jenis kupu-kupu indah sebagai materi pengayaan keanekaragaman hayati di SMPN sekitar TWA Suranadi dalam kegiatan pengabdian ini terlaksana dengan baik dengan antusiasme peserta kegiatan yang tinggi.

Kata kunci: Sosialisasi, Keanekaragaman hayati, Kupu-kupu, Suranadi.

\section{Pendahuluan}

Pendidikan memegang peranan dan faktor yang sangat penting dalam kehidupan manusia karena merupakan salah satu wahana untuk menciptakan sumberdaya manusia yang berkualitas dalam hal pengetahuan dan keterampilan agar memiliki kemampuan berpikir kritis, kreatif, dan sikap terbuka. Meningkatkan kualitas sumberdaya manusia merupakan tujuan atau sasaran bidang pendidikan dalam menyikapi era globalisasi. Dalam era globalisasi ini, sumberdaya manusia yang 
Liwa et al, Jurnal Pengabdian Masyarakat Sains Indonesia 2020, 2 (2): 137-142. DOI : https://doi.org/10.29303/jpmsi.v2i2.79

berkualitas akan menjadi tumpuan utama suatu bangsa dalam berkompetisi. Oleh karena itu, sudah seharusnya pembangunan di sektor pendidikan menjadi prioritas utama yang harus dilakukan pemerintah agar melahirkan generasi-generasi bangsa yang berintelektual (Rahmayanti, 2015).

Ilmu Pengetahuan Alam (IPA) berkaitan dengan cara mencari tahu tentang alam secara sistematis, sehingga IPA bukan hanya penguasaan kumpulan pengetahuan yang berupa fakta-fakta, konsep-konsep, atau prinsip-prinsip saja tetapi juga merupakan suatu proses penemuan (Suharto, 2018; Rahmawati, 2018). Proses pembelajarannya menekankan pada pemberian pengalaman langsung untuk mengembangkan kompetensi agar menjelajahi dan memahami alam sekitar siswa secara ilmiah (Kurnianingsih, 2012). Tetapi pada kenyataan di lapangan, tidak semua sekolah dapat menerapkan pembelajaran sesuai dengan tuntutan kurikulum 2013, seperti pada beberapa sekolah di sekitar kawasan Suranadi menunjukkan bahwa hasil belajar IPA siswa banyak di bawah kriteria ketuntasan minimum (KKM) 7,5. Hasil observasi dan wawancara dengan guru IPA (Nia Fahmi, S.Pd.) dan Kepala Sekolah sekolah mitra (Aendi, S.Pd.) sekolah mitra diketahui bahwa penyebab rendahnya hasil belajar tersebut disebabkan karena pembelajaran yang monoton dan tidak menggunakan media pembelajaran yang baik.

Mengatasi masalah pembelajaran tersebut, diperlukan sebuah strategi belajar yang tidak mengharuskan siswa menghafal fakta-fakta, tetapi strategi yang mendorong siswa mengkonstruksikan pengetahuan dibenak mereka sendiri. Dalam konteks ini siswa perlu mengerti makna belajar beserta manfaatnya. Untuk itu diperlukan suatu pendekatan yang tepat. Salah satu pendekatan belajar yang sesuai dengan kebutuhan siswa SMP pada umumnya yaitu pendekatan belajar dimana siswa langsung diajak berkenalan dengan lingkungan sekitarnya (Inayah Iin 2016; Angela Lia, 2018). Dalam hal ini materi IPAyang diberikan dikaitkan dengan hal-hal atau benda-benda yang ada di lingkungan siswa dan sering ditemuinya. Pembelajaran seperti ini disebut pembelajaran kontekstual (Samriani, 2018).

Ada kecenderungan sekarang ini bahwa anak akan belajar lebih baik jika lingkungan diciptakan alamiah. Belajar akan lebih bermakna jika anak mengalami apa yang dipelajarinya, bukan mengetahuinya (Ilhamdi, 2020). Pendekatan ContextualTeaching and Learning (CTL)
e-ISSN : 2715-2537

p-ISSN : 2715-2545

merupakan konsep belajar yang membantu guru mengaitkan materi yang diajarkan dengan situasi dunia nyata dan mendorong peserta didik membuat hubungan antara pengetahuan yang dimilikinya dengan penerapannya dalam kehidupan mereka sebagai anggota keluarga dan masyarakat (Hadiyanta, 2013). Pembelajaran CTL melibatkan para siswa dalam aktivitas penting yang membantu mereka mengaitkan pelajaran akademis dengan kehidupan nyata yang mereka hadapi (Angela, 2018).

Trianto (2012) Pembelajaran kontekstual atau Contekstual Teaching and Learning suatu pendekatan pembelajaran yang menekankan kepada proses keterlibatan siswa secara penuh untuk dapat menemukan materi yang dipelajari dan menghubungkannya dengan situasi kehidupan nyata sehingga mendorong siswa untuk dapat menerapkannya dalam kehidupan mereka. Pembelajaran kontekstual memandang bahwa belajar bukanlah menghafal, akan tetapi belajar adalah proses pengalaman dalam kehidupan nyata. Pengajaran dengan menggunakan pembelajaran kontekstual mendorong anak agar dapat menemukan makna dari pembelajaran dengan menghubungkan materi yang dipelajari dengan situasi kehidupan nyata, sehingga pengetahuan yang didapat akan tertanam erat dalam memorinya Pembelajaran kontekstual merupakan sebuah sistem yang menyeluruh dan terdiri dari bagian bagian yang saling terhubung. Jika bagian-bagian ini terjalin satu sama lain maka akan membuat para siswa mampu membuat hubungan yang menghasilkan makna. Dalam pembelajaran kontekstual terdapat tujuh elemen penting, yaitu inkuiri, pertanyaan, konstruktivistik, pemodelan, masyarakat belajar, penilaian autentik, dan refleksi. Ketujuh unsur tersebut dapat diaplikasikan dalam keseluruhan proses pembelajaran.

Penerapan model pembelajaran Contextual Teaching and Learning (CTL), akan terjalin suasana belajar yang mengutamakan kerja sama, saling menunjang, menyenangkan, tidak membosankan, belajar dengan bergairah, pembelajaran terintegrasi, menggunakan berbagai sumber, siswa aktif, sharing dengan teman, siswa kritis, guru kreatif. Pembelajaran berlangsung secara alamiah dalam bentuk kegiatan siswa bekerja dan mengalami, bukan transfer pengetahuan dari guru. Siswa dapat mengkonstruksikan sendiri pengetahuannya, menemukan sendiri konsep-konsep materi yang 
Liwa et al, Jurnal Pengabdian Masyarakat Sains Indonesia 2020, 2 (2): 137-142. DOI : https://doi.org/10.29303/jpmsi.v2i2.79

sedang dihadapi (Hadiyanta, 2013; Fatonah dkk., 2013).

Penerapan strategi pembelajaran, tentunya akan lebih menunjang dengan adanya media pembelajaran. Media pembelajaran merupakan salah satu alat komunikasi dalam proses pembelajaran. Penggunaan media pembelajaran sangat membantu guru mengembangkan dan memperdalam proses belajar mengajar di kelas. Penggunaan media pembelajaran yang bervariasi dengan tepat dapat mempengaruhi aktivitas, minat dan motivasi belajar siswa yang tentunya akan mempengaruhi prestasi belajarnya. Sesuai dengan tujuan pembelajaran Ilmu Pengetahuan Alam (IPA) berupa hafalan dan rumus yang sukar diingat, sehingga proses pembelajarannya terasa membosankan, maka diperlukan media yang tepat dalam kegiatan pembelajaran. Dalam kegiatan pengabdian ini akan diterapkan buku suplemen dan VCD berbasis lingkungan sebagai alternatif solusi untuk menghadirkan pembelajaran berkualitas pada sekolah di kawasan ekowisata Suranadi. Dengan media VCD siswa dapat melihat, mendengarkan menyaksikan langsung materi pembelajaran yang ada (Suwatno, 2012).

Pembelajaran materi keanekaragaman hayati sangat penting membelajarkan siswa dengan media VCD karena dapat pandang dengar materi pelajaran tersebut, apalagi materinya berasal dari lingkungan sekitar siswa (Angelia, 2018). Seperti keanekaragaman hayati yang ada di lingkungan siswa sekolah sekitar TWA Suranadi kupu-kupu indah, capung dan serangga lain sangat banyak jenisnya dan menarik (Ilhamdi, 2018; Ilhamdi, 2019). Pembelajaran keanekaragaman hayati kupukupu ini menarik karena warnanya indah dan
e-ISSN : 2715-2537

p-ISSN : 2715-2545

singgah pada tumbuhan yang berbunga menarik demikian pula mudah untuk dikenal (Peggie, 2011; Duara, 2014; Haidar dkk., 2017). Namun tidak pernah secara pasti diketahui oleh siswa sekitar TWA Suranadi karena materi yang disampaikan oleh gurunya adalah keanekaragaman hayati di buku paket IPA yang umum padahal sekitar siswa banyak keanekaragaman hayati makhluk hidup.

\section{Metode}

Metode Pelaksanaan yang diterapkan pada kegiatan pengabdian ini berupa sosialisasi dengan melaksanakan pembelajaran kontektual dengan menggunakan buku dan VCD pembelajaran yang kontektual (berisi materi pelajaran dari lingkungan sekitar siswa yaitu berbagai jenis kupu-kupu indah yang ada di sekitar siswa). Secara rinci metode pelaksanaan pengabdian ini adalah :

1. Pembelajaran langsung

Pelaksanaan kegiatan dengan menerapkan pembelajaran kontekstual bagi siswa menggunakan buku dan VCD pembelajaran berbasis lingkungan.

2. Diskusi dan tanya jawab

Diskusi dan tanya jawab tentang hal-hal terkait materi yang telah disampaikan.

3. Evaluasi dan refleksi

Kegiatan pada tahap ini untuk memastikan materi sosialisasi dipahami betul oleh peserta.

4. Pendampingan

Kegiatan pendampingan dilakukan agar pelaksanaan pembelajaran berbasis lingkungan pada pembelajaran selanjutnya terlaksana dengan baik di sekolah mitra. 
Adapun langkah-langkah kegiatan dapat dilihat pada gambar 1.

\begin{tabular}{|l|l|l|l|l|}
\hline \multicolumn{1}{|c|}{$\begin{array}{c}\text { TAHAP } \\
\text { Persiapan }\end{array}$} & \multicolumn{1}{c|}{$\begin{array}{c}\text { TAHAP } \\
\text { Pelaksanaan }\end{array}$} \\
\hline $\begin{array}{l}\text { Studi Literatur } \\
\text { Need Analisis } \\
\text { Pelaporan }\end{array}$ \\
\hline $\begin{array}{l}\text { Penyusunan Isi } \\
\text { Pelatihan }\end{array}$
\end{tabular}

Gambar 1. Tahapan Pelaksanaan Kegiatan

Pada tahap persiapan dilakukan analisis kebutuhan penyusunan materi pelatihan koordinasi dengan pihak sekolah serta penyusunan jadwal pelaksanaan kegiatan. Tahap pelaksanaan akan diberikan Sosialisasi Berbagai Jenis Kupu-Kupu Indah sebagai Materi Pengayaan Keanekaragaman Hayati di SMPN Sekitar Kawasan Taman Wisata Alam Suranadi . Tahap evaluasi dan pelaporan dilakukan analisis untuk mengetahui ketercapaian dari tujuan kegiatan.

\section{Hasil dan Pembahasan}

\section{a. Kegiatan Sosialisasi}

Sosialisasi dilakukan pada peserta kegiatan pengabdian yang terdiri dari 21 orang berasal dari guru-guru SMPN di sekitar Kawasan Taman Wisata Alam Suranadi yaitu SMPN 5 Narmada, SMPN 1 Narmada, SMPN 2 Lingsar Lombok Barat. Kegiatan sosialisasi dilakukan untuk memberikan penjelasan yang komprehensif kepada peserta tentang berbagai jenis kupu-kupu indah sebagai materi pengayaan Keanekaragaman Hayati di SMPN Sekitar Kawasan Taman Wisata Alam Suranadi oleh tim pengabdian. Kegiatan sosialisasi menjawab keraguan dan pertanyaan peserta kegiatan melalui aktifitas penyampaian materi, tanya jawab dan diskusi.
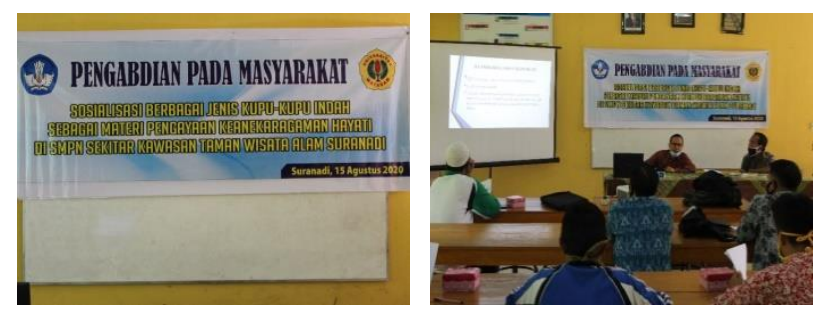

Gambar 2. Kegiatan Sosialisasi, Penjelasan Tim Pengabdian

b. Kegiatan Memperkenalkan Buku dan menyaksikan VCD Pembelajaran Kupu-Kupu

1. Kegiatan Memperkenalkan Buku KupuKupu

Isi Buku Berbagai jenis kupu-kupu di Taman Wisata Alam Suranadi dibagikan kepada seluruh peserta untuk melihat dan mengenal isinya. Selain juga ditayangkan melalui layer berbagai jenis kupu-kupu yang ada di TWA Suranadi. Peserta antusias melihat dan mengenal isi buku karena buku ini mengandung materi keanekaragaman jenis makhluk hidup kupu-kupu indah yang ada di sekitar siswa yang belum ada selama ini. Buku yang ada untuk pembelajaran biasanya tentang keanekaragaman makhluk hidup yang ada di luar lingkungan tempat tinggal siswa. Selain itu atusiasme peserta bertambah karena buku ini menarik, 
Liwa et al, Jurnal Pengabdian Masyarakat Sains Indonesia 2020, 2 (2): 137-142. DOI : https://doi.org/10.29303/jpmsi.v2i2.79

menampilkan gambar warna dari kupu-kupu indah yang berwarna warni tersebut.

Buku ini menyajikan keanekaragaman hayati makhluk hidup kupu-kupu sebanyak 40 jenis dan 569 individu yang termasuk dalam famili Papilionidae, Nymphalidae, Pieriidae, Lycaenidae dan Hesperiidae. Indeks keanekaragaman seluruh jenis di Taman Wisata Alam Suranadi diperoleh 3,47 dan indeks dominansi seluruh jenis diperoleh 0,03. Pola distribusi kupu-kupu di TWA Suranadi termasuk mengelompok, kecuali Troides helena memiliki distribusi teratur. Adapun kategori keanekaragaman spesies kupu-kupu di Taman Wisata Alam Suranadi dengan indeks keanekaragaman 3,47 yang tergolong tinggi.

2. Kegiatan menyaksikan VCD Pembelajaran

Selain memperkenalkan buku yang berisi berbagai jenis kupu-kupu yang ada di Taman Wisata Alam Suranadi juga disajikan VCD Pembelajaran yang berisi tentang keanekaragaman makhluk hidup kupu-kupu di TWA Suranadi. Hal ini dilaksanakan agar media tentang materi pembelajaran keanekararagaman makhluk hidup dapat tersedia baik berupa buku maupun VCD sehingga siswa maupun guru lebih mudah membelajarkan materi tersebut.

3. Kegiatan Tanya Jawab dan Diskusi Peserta dengan Tim Pengabdian

Kegiatan ini berlangsung setelah kegiatan sosialisasi, penjelasan, pengenalan buku dan menyaksikanVCD Pembelajaran tentang berbagai jenis kupu-kupu indah di Taman Wisata Alam Suranadi. Peserta sangat antusias menanggapi, bertanya dan berdiskusi tentang topik ini karena peserta ingin sekali membelajarkan keanekaragaman hayati makhluk hidup dengan mengambil contoh makhluk hidup yang ada di sekitar siswa (pembelajaran kontekstual)

\section{Kesimpulan}

Kesimpulan dari kegiatan ini adalah:

1. Seluruh peserta kegiatan pengabdian sosialisasi berbagai Jenis Kupu-Kupu Indah sebagai Materi Pengayaan Keanekaragaman Hayati di SMPN Sekitar Kawasan Taman Wisata Alam Suranadi sangat antusias.
e-ISSN : 2715-2537

p-ISSN : 2715-2545

2. Materi sosialisasi $100 \%$ peserta mengikuti dan memahami isi kegiatan pengabdian.

3. Berbagai jenis kupu-kupu indah dapat diterapkan sebagai materi pengayaan keanekaragaman hayati di SMPN sekitar Kawasan TWA Suranadi.

\section{Saran}

Kegiatan seperti ini diharapkan bisa menginspirasi banyak kalangan untuk melakukan kegiatan pengabdian serupa namun dengan tema yang lebih beragam.

\section{Ucapan Terima Kasih}

Penulis mengucapkan terma kasih kepada Universitas Mataram dan Lembaga Penelitian dan Pengabdian kepada Masyarakat (LPPM) yang telah membiayai kegiatan pengabdian ini serta kepada warga sekolah di SMPN sekitar taman wisata Suranadi yang telah membantu kegiatan ini sehingga dapat terlaksana dengan baik.

\section{Daftar Pustaka}

Angela Lia, 2018, Pengembangan Modul Biologi Berbasis Contextual Teaching and Learning (CTL) pada Materi Keanekaragaman Hayati Kelas X Madrasah Aliyah, Jurnal Edukasi Matematika dan Sains Vol. 6 no.2 : 93 102

Duara, P., Kalita, J. 2014. Butterfly as Pollinating Insects of Flowering Plants. Global Journal of Science Frontier Research (C), Vol. 14(1): 1 - 5

Haidar, IKA., Ahsan, MF., and Kabir, MT. 2017. Species diversity and habitat preference of butterflies (Insecta: Lepidoptera) in Inani Reserve Forest of Cox's Bazar, Bangladesh. Journal of Insect Biodiversity and Systematics, Vol.3(1): 47-67

Fathonah, Rani S., Sugiharto, dan Suryadi Budi U. 2013. Studi Komparasi Penggunaan Media Teka-Teki Silang(TTS) Dengan Kartu pada Pembelajaran Kimia melalui Pendekatan Contextual Teaching And Learning (CTL) terhadap Prestasi Belajar Siswa Pada Materi ZatAdiktif Dan 
Liwa et al, Jurnal Pengabdian Masyarakat Sains Indonesia 2020, 2 (2): 137-142. DOI : https://doi.org/10.29303/jpmsi.v2i2.79

Psikotropika Kelas VIII SMPN 2 Ngadirojo,Wonogiri Tahun Pelajaran 2011/2012. Jurnal Pendidikan Kimia (JPK). Vol 2(3): Hal 68-76.

Febrita, E., Yustina, Dahmania. 2014. Keanekaragaman jenis kupu-kupu (subordo rhopalocera) di kawasan wisata hapanasan rokan hulu sebagai sumber belajar pada konsep keanekaragaman hayati. Jurnal biogenesis. Vol. 10 (2)

Hadiyanta, Nur. 2013. Penerapan Model Pembelajaran Contextual Teaching and Learning (CTL) untuk Meningkatkan Hasil Belajar PKN. Jurnal Kependidikan. Vol 43(1): Hal. 32 - 38.

Ilhamdi, ML, 2018, Pola Penyebaran Kupu-kupu Di Kawasan Taman Wisata Alam Suranadi Lombok Barat, Jurnal Biologi Tropis 18(1) : 19-25

Ilhamdi ML., Mertha IG, 2020, Application Of Cooperative Learning Model For Group Investigation Type In General Biology Learning, Jurnal Pijar MIPA Vol. 15 no. 1

Ilhamdi, ML, Al Idrus, A, Santoso D. 2019. Struktur Komunitas Kupu-Kupu di Taman Wisata Alam Suranadi, Lombok Barat, Jurnal Biotropis 19 (1) :

Inayah iin, 2016, Penerapan Model Pemebelajaran

Contextual Teaching And Learning Pada

Konsep Keanekaragaman Makhluk Hidup

Dan Upaya Pelestariannya Terhadap

Prestasi Belajar, Jurnal Quangga Vol.8

no. $1: 49-51$

Kurnianingsih, 2012, Efektivitas Pembelajaran CTL dalam meningkatkan kompetensi dasar sain di SMP kota Pontianak, Jurnal Guru Membangun Vo. 24 (2)

Peggie D. dan Amir M., 2011, Practical guide to Butterflies, Puslit LIPI and NNEF Shitaya, Japan

Rahmayanti, 2015, Penggunaan Media IT Dalam Pembelajaran, Jurnal Ilmiah CIRCUIT Vol.1(1) : 85-97

Rahmawati T, 2018, Penerapan model pembelajaran ctl untuk Meningkatkan hasil belajar siswa sekolah Dasar pada mata pelajaran IPA, Jurnal Ilmiah pendidikan dan Pembelajaran Vol. 2 (1) : $12-20$
e-ISSN : 2715-2537

p-ISSN : 2715-2545

Samriani, 2018, Penerapan Pendekatan Contextual

Teaching And Learning (CTL) Dalam

Meningkatkan Hasil Belajar Siswa Pada

Mata Pelajaran IPA di Kelas IV SDN No

3 Siwalempu, Jurnal Kreatif Tadulako

Online Vol. (2) : 56-74

Suharto, 2018, Peningkatan pembelajaran IPA melalui pendekatan Contekstual Teaching and Learning (CTL) di kelas VI SDN 45 Jambak Kecamatan Bayang, Jurnal Penelitian Guru Indonesia Vol.3 (1).

Suwatno, 2012, Pengembangan media VCD konteks pertanian pada pembelajaran bahasa Indonesia aspek mendengarkan dan menulis pengumuman di SD kelas IV semester 2, Jurnal Seloka Vol 1 (1) : 6468.

Trianto. 2012. Model Pembelajaran Dalam Teori dan Praktek. Jakarta: Prestasi Pustaka. 